\title{
Interpretation of unsaturated soil behaviour in the stress - Saturation space, I: Volume change and water retention behaviour
}

\author{
An-Nan Zhou ${ }^{\mathrm{a}, *}$, Daichao Sheng ${ }^{\mathrm{b}, 1}$, Scott W. Sloan ${ }^{\mathrm{b}, 2}$, Antonio Gens ${ }^{\mathrm{c}, 3}$ \\ ${ }^{a}$ School of Civil, Environmental and Chemical Engineering, Royal Melbourne Institute of Technology (RMIT), Melbourne, VIC 3001, Australia \\ ${ }^{\mathrm{b}}$ Centre for Geotechnical and Materials Modelling (CGMM), School of Engineering, The University of Newcastle, NSW 2308, Australia \\ ${ }^{\mathrm{c}}$ Department of Geotechnical Engineering and Geosciences, Universitat Politecnica de Catalunya, Barcelona, Spain
}

\section{A R T I C L E I N F O}

\section{Keywords:}

Unsaturated soil

Compressibility

Bonding/debonding effects

Effective degree of saturation

Bishop effective stress

Hydraulic hysteresis

Hydro-mechanical interaction

\begin{abstract}
A B S T R A C T
Unsaturated soil behaviour, such as volume change, shear strength and yield stress, is usually interpreted and modelled in terms of stress and suction. This approach is consistent with laboratory tests where suction is a controllable variable. However, it also suffers some limitations. This paper (Parts I and II) presents an alternative approach for interpreting unsaturated soil behaviour, which is built in the space of stress versus degree of saturation. In Part I, a new volume change equation is proposed in terms of stress and degree of saturation, to give a better explanation to the non-linear change of soil compressibility under constant suctions. The soil compression index is assumed to be a function of the effective degree of saturation and is interpolated from the known compressibility at the fully saturated state and that at a dry state. An alternative approach to simulate hydraulic hysteresis and hydro-mechanical interaction is then introduced, which enables the calculation of the effective degree of saturation under complex stress and suction paths. The proposed volume change equation and the approach to describe saturation variation, which are two fundamental aspects to establish constitutive laws for unsaturated soils, are validated against a variety of experimental data in literature.
\end{abstract}

(c) 2012 Elsevier Ltd. All rights reserved.

\section{Introduction}

Constitutive modelling of unsaturated soils generally involves the extension of constitutive models for saturated states to unsaturated states. Such an extension is usually realised by treating suction as an additional variable in the stress space. In doing so, suction is used as a fundamental variable in characterising the mechanical and hydraulic behaviour of unsaturated soils. Most models in the literature use suction either as a stress (external) variable or as a hardening (internal) variable. Some of these models are established in the space of net stress and suction (e.g., $[1,6,5,43,32]$, whereas others are in the space of effective stress [2] and suction (e.g., [18,3,22,35,36,49,8,50,34,40,25]. Irrespective of the stress variables used, there are some common features of these models:

\footnotetext{
* Corresponding author. Tel.: +61 3 99250407; fax: +61 396390138.

E-mail addresses: Annan.Zhou@rmit.edu.au (A.-N. Zhou), Daichao.Sheng@ newcastle.edu.au (D. Sheng), Scott.Sloan@newcastle.edu.au (S.W. Sloan), Antonio.Gens@upc.edu (A. Gens).

1 Tel.: +612 49215746; fax: +612 49216991 .

2 Tel.: +61 2 49216059; fax: +61249216991.

3 Tel.: +3493 4016867; fax: +34934017251.
}

(a) The volume change equation (or at least the compression index) of the soil is a function of suction.

(b) The yield surface or the elastic zone is defined in the space of stress versus suction.

(c) The shear strength is defined in terms of stress and suction (or degree of saturation).

The above approach of constitutive modelling of unsaturated soils is consistent with common laboratory tests, where suction is usually a controllable and independent variable. For example, it is common to study the volume change behaviour of unsaturated soils under constant suctions, and as such the soil volume (voids ratio, specific volume or volumetric strain) is usually plotted against logarithmic stress for constant suctions. It is also common to study the yield stress and shear strength behaviour as functions of suction.

Although convenient, this approach of treating suction as an additional variable suffers from some significant limitations. As noted by Sheng et al. [33], the volume change equation which underpins the yield surface and shear strength criteria is a fundamental component required to extend a saturated soil model to an unsaturated state. Therefore, the volume change equation is used here to demonstrate the limitations of models established in the suction-stress space. In such an equation, the compression index 


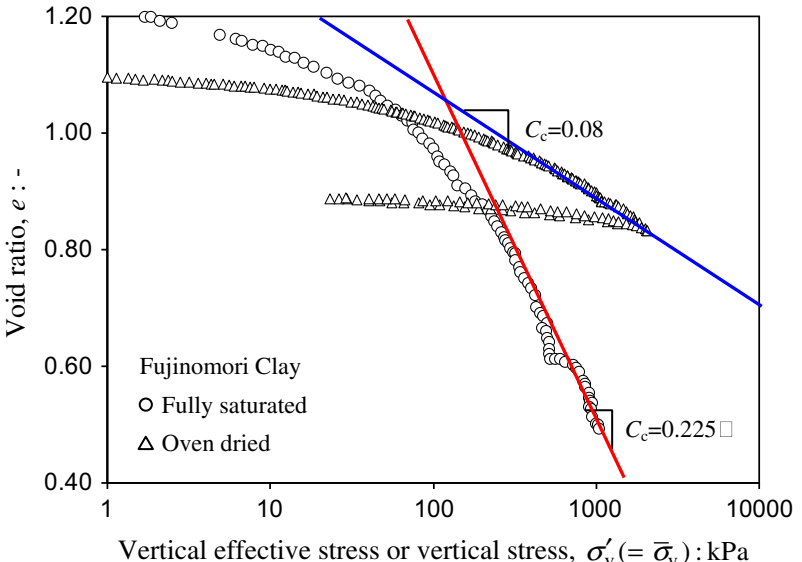

Fig. 1. Oedometer compression tests of fully saturated and oven dried Fujinomori clay (data after $[20,19]$

( 2 ) that defines the volume change per logarithmic unit change of mean stress under constant suction is usually assumed to be a function of suction ( $(s)$. In some models this compressibility function is assumed to decrease with suction [1], whereas in other models it is assumed to increase to with suction [44,39]. Both options seem to have solid experimental support.

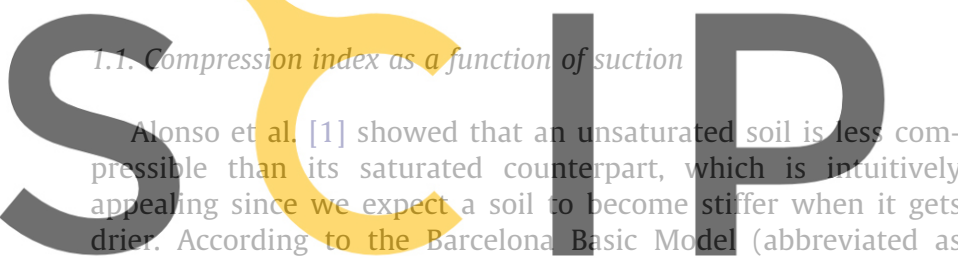
BBM usually [1], the compression index of a completely dry soi $(s \rightarrow \infty)$ is only a fraction of that for a saturated soil, i.e.

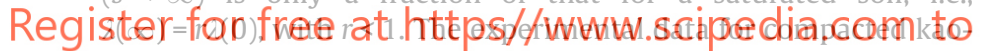
lin and Lower Cromer till $[24,14,1]$ indicate that the values of $r$ are around 0.25. One-dimensional compression test results for saturated, air-dried and oven-dried Fujinomori clay specimens have been presented by Li et al. [20,19]. The compression index for the fully saturated specimen is about 0.225 , but decreases to about 0.08 for oven-dried specimen (see Fig. 1). Uygar and Doven [46] presented oedometer compression test results for saturated and dry sand commonly found in the southeast coast of Cyprus. These show that, under the same relative density $\left(I_{d}\right)$, the compression index of the saturated sand is about twice larger than that of the dry specimens (Fig. 2). On the other hand, the experimental data given

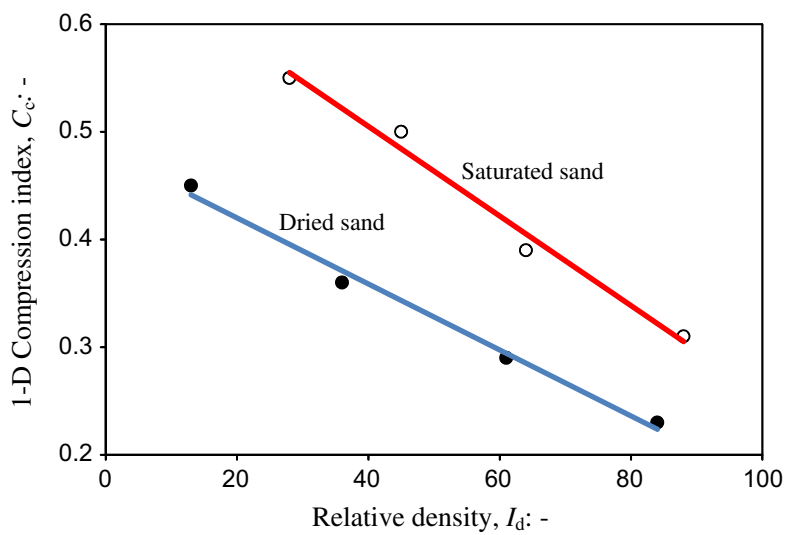

Fig. 2. Compression index for both dried and saturated sands (data after [46].
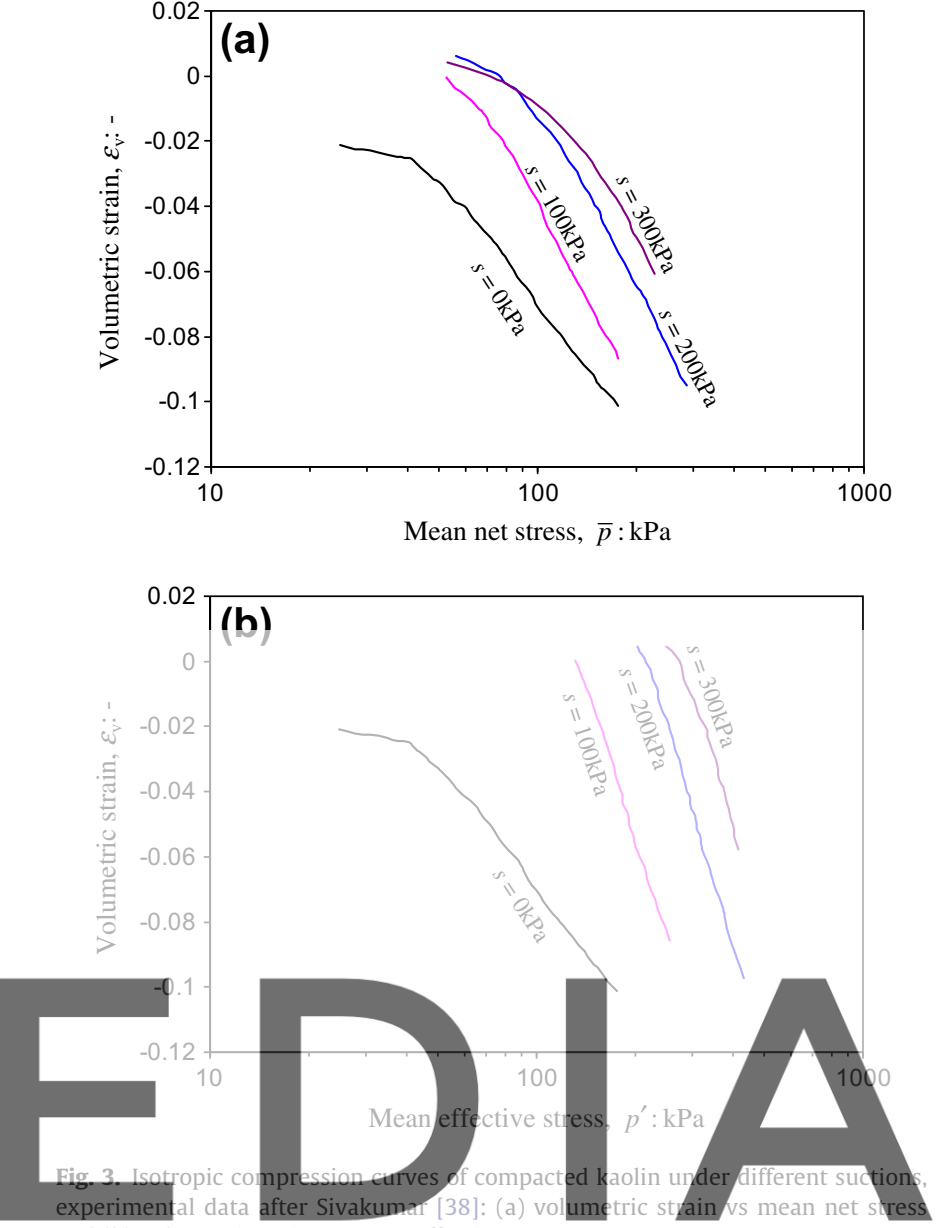

and (b) volumetric stain vs mean effective stress.

\section{download the version without the watermark by Toll [44], Toll and Ong [45], Sivakumar [38], Sharma [30] and Sivakumar and Wheeler [39] all suggest that the compression in-} dex (in either net stress or Bishop effective stress space) increases with increasing suction (Fig. 3). The justification for this increase in compressibility is that drying a saturated soil tends to create highly compressible macro-pores in the soil $[29,8]$.

In addition to the conflicting features of soil compressibility mentioned above, expressing the compressibility as a function of suction, i.e. $\lambda(s)$, also suffers some other significant shortcomings, particularly in the Bishop effective stress space where only one compression index is used both for stress and suction changes. For example, a decreasing $\lambda(s)$ with increasing suction implies that the wetting-induced collapse volume always increases with increasing stress, which does not agree with most experimental observations (e.g. [41]. Experimental data $[41,17]$ typically show that the collapsible volume first increases and then decreases with increasing stress level as shown in Fig. 4. It should be noted that, in the effective stress space, an unsaturated normal compression line (NCL) parallel to the saturated NCL would still lead to an ever increasing collapse volume with increasing stress, because the suction effect on the logarithmic effective stress is less significant at higher net stresses.

On the other hand, it is also common to assume that the normal compression line shifts with suction in the space of logarithmic mean effective stress versus specific volume. Under such an assumption, the compression index $\lambda(s)$ can increase with increasing suction, such as in the model of Gallipoli et al. [8], hence leading to a more reasonable collapse potential where the collapse volume decreases with increasing stress. However, such an 


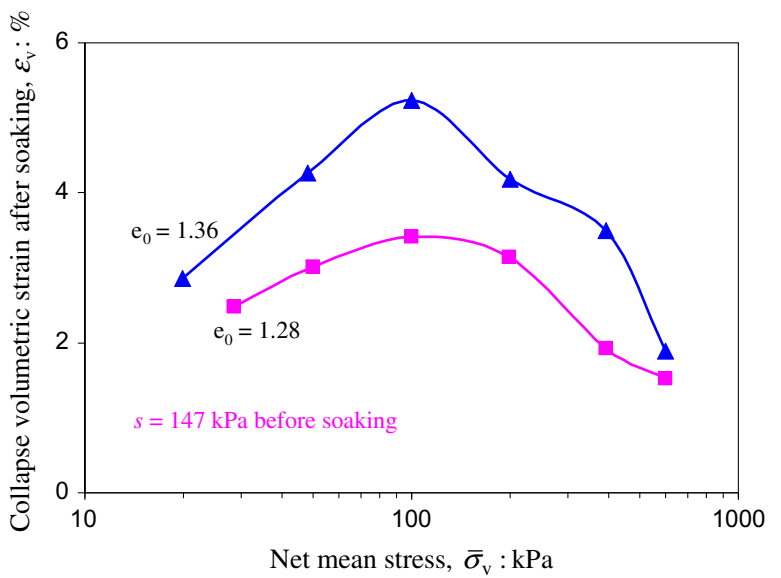

Fig. 4. Collapse volumetric strain after soaking at various degrees of saturation under different net stresses (experimental data after [41].

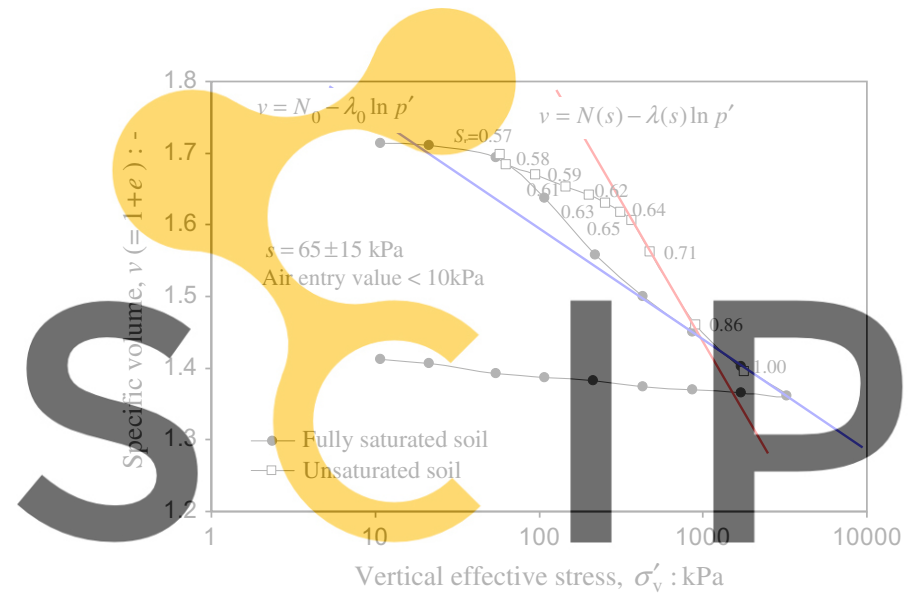

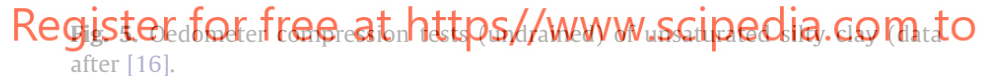

approach also suffers a theoretical defect. It essentially implies that neutral loading along the current yield surface can cause yield surface expansion (hardening), as pointed out by Sheng [31]. Another minor theoretical problem with this approach is that the normal compression line for an unsaturated state will cross the saturated normal compression line, as shown in Fig. 5. The experimental data of Honda [13] and Jotisankasa [16] indicates that NCLs for unsaturated states under constant suctions will gradually approach, but never cross, the saturated NCL.

Other researchers have also noticed the above problems and sought alternative solutions. For example, Georgiadis et al. [12] assumed the compression index as a function of stress. The problems discussed above are somewhat alleviated if a net stress approach is adopted to describe the volume change. In this approach, the volume change equation usually involves two separate compression indices, one for stress change and the other for suction change. As a consequence, the compression index related to stress change is not subjected to any theoretical constraint [31]. For example, Josa et al. [15] assumed that $\lambda(s)$ increases with increasing suction at high stresses, in contrast to Alonso et al. [1].

\subsection{Compression index as a function of degree of saturation}

Experimental data on the volume change of unsaturated soils usually do not support a constant compression index for a constant suction. Fig. 5 implies that it is possible to saturate an unsaturated soil by compression while the suction is kept constant, which suggests that the compression index should be a function of the degree of saturation instead of suction. Based on the experimental data mentioned above, it is logical to assume that the compression index decreases with a decreasing degree of saturation. Compression under constant suction will raise the degree of saturation (see Fig. 5) which, in turn, increases the compressibility of the soil. The increase in soil compressibility is likely due to the debonding effect of unsaturated soil, i.e. stress-induced collapse of macropores. Therefore, the compression index of an unsaturated soil under a constant suction can change from a small value at lower stresses to a larger value at intermediate stresses and, finally, approach the compression index value for the saturated condition at higher stresses. The seemingly conflicting behaviour of soil compressibility mentioned above can indeed be explained consistently.

Treating the soil compressibility as a function of the degree of saturation inevitably leads to a yield surface and a shear strength surface that are dependent on the degree of saturation. This feature has been considered unviable in constitutive modelling, mainly due to two facts: (1) the non-unique relationship between the degree of saturation and suction would lead to non-unique yield surface and shear strength surface in the stress-suction space, (2) the degree of saturation (unlike suction) is not a controllable variable in laboratory tests and it is hence difficult to establish constitutive laws (such as the volume change equation) based on the degree of saturation [31]. In this paper, however, we will explore the possibility of using the degree of saturation instead of suction as the

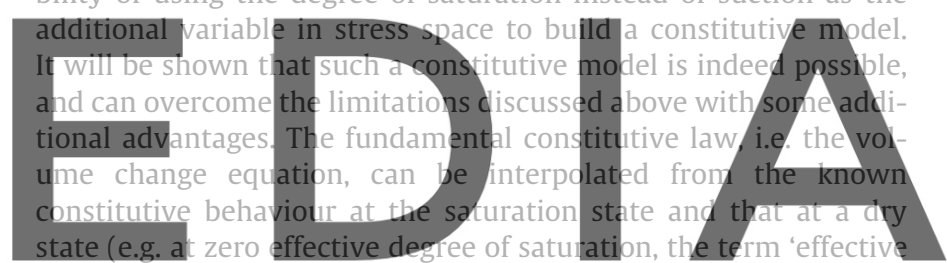

degree of saturation' will be defined in Eq. (1) in the next section) If suction is eliminated from being a state variable in the constitu-

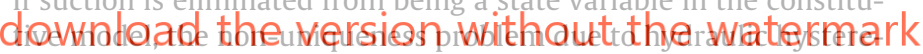
sis is automatically solved.

In passing, it is noted that the constitutive model built in the stress-saturation space is consistent with the finite element method where the displacements and pore pressures are first solved from the equilibrium and continuity equations. The strains and suctions are solved from the displacements and pore pressures, while the degree of saturation is solved in the same way as the stresses at integration points. In this context, the degree of saturation is indeed similar to the stresses, as noted by Sheng et al. $[35,36]$.

\subsection{Stress variables}

Another important consideration concerns the stress variables to be used to build a constitutive model for unsaturated soils. Most constitutive models are either established in the net stress and suction space, or in the Bishop effective stress and suction space. Sheng [31] and Gens [11] have discussed the advantages and disadvantages of each group. In this paper, our goal is to replace suction by the degree of saturation as a state variable for modelling unsaturated behaviour. In the models based on net stress, the matric suction is usually a central variable and cannot easily be eliminated from the constitutive formulation. We will show that it is possible to eliminate suction from the models based on the Bishop effective stress. The cost is that the stress space (Bishop effective stress versus degree of saturation) is no longer explicit and the representation of laboratory tests becomes more difficult, a common feature of involving the degree of saturation in stress variables. 
The paper is organised as follows. A new volume change equation is first proposed to model normally consolidated unsaturated soils. This equation is used to explain the compressibility change due to saturation change. The proposed volume change equation is then validated against a variety of experimental data in literature. Because the degree of saturation plays a very important role in the proposed volume change equation, an approach to describe saturation change with stress or suction changes is then introduced. This approach can be used to simulate hydro-mechanical interaction and the hydraulic hysteresis of soil water retention behaviour. The performance and validation of the proposed approach for saturation variation are presented in the last section in this paper. The volume change and saturation change equations are generalised into a three-dimensional constitutive model for the coupled hydro-mechanical behaviour of the soil under general stress and suction states in a companion paper [51].

\section{Normally consolidated lines for unsaturated soils}

\subsection{Basic stress variable}

Our goal here is to build constitutive equations in the space of Bishop's effective stress versus the effective degree of saturation. The effective degree of saturation is defined as

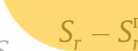

$S_{e}=\frac{S_{r}-S_{r}^{r e s}}{S^{0}-S^{r e s}}$
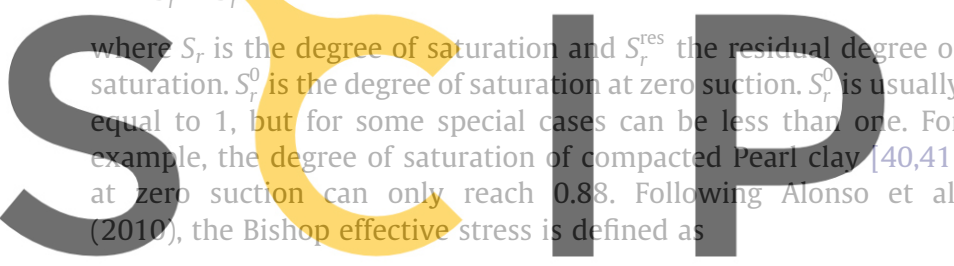

$\sigma_{i j}^{\prime}=\bar{\sigma}_{i j}+S_{e} S \delta_{i j}$

$(2$

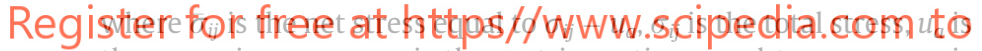
the pore air pressure, $s$ is the matric suction equal to $u_{a}-u_{w}, u_{w}$ is the pore water pressure, and $\delta_{i j}$ is the Kronecker delta. In this paper, the effective stress $\left(\sigma^{\prime}\right)$ defined in Eq. (2) is selected as the basic stress variable for constitutive modelling.

\subsection{Volume change equation}

In the space of $v$-In $p^{\prime}$, the normal compression lines (i.e., volume change equation) for both saturated and unsaturated soil are assumed to take the following form:

$v=N-\lambda\left(S_{e}\right) \ln p^{\prime}$

where $p^{\prime}$ is the mean effective stress and $N$ is the intercept of the normal compression lines with the $v$-axis when In $p^{\prime}=0$.

Eq. (3) states that the isotropic compression line for a normally consolidated soil is a straight line when the effective degree of saturation is kept constant. The parameter $N$ essentially corresponds to the state where the soil has not undergone any consolidation. Once elastoplastic deformation occurs, the state point will move to a new position along the normal compression line. Hence, the initial state of a NCL for any saturation status should be the same. In addition, a varying $N$ (with suction or with saturation) will lead to non-uniqueness in soil shear strength and yield stress, as pointed out by Sheng [31]. A constant $N$ means that the effect of drying on the soil volume can be offset by applying an isotropic tensile stress to the soil, one of the implications of using an effective stress. Therefore, a constant $N$ is adopted in this paper.

The compression index $\lambda\left(S_{e}\right)$ is assumed to be a function of the effective degree of saturation, and can be interpolated from the compression indices for the saturated state and the driest state $\left(S_{e}=0\right)$. For a sandy soil, the driest state is dry sand where the water content is close to zero while, for a clayey soil, the driest state corresponds to the residual water content. The compression index for a partially saturated state thus lies between these two limiting values. One of the simplest non-linear interpolation functions for $\lambda\left(S_{e}\right)$ takes the following form:

$\lambda\left(S_{e}\right)=\lambda_{0}-\left(1-S_{e}\right)^{a_{1}}\left(\lambda_{0}-\lambda_{d}\right)$

where $\lambda_{0}$ is the compression index for the saturated state $\left(S_{e}=1\right), \lambda_{d}$ is the compression index for the driest state $\left(S_{e}=0\right)$, and $a_{1}$ is a fitting parameter that defines the variation of compression index with the effective degree of saturation. Parameter $a_{1}$ can be calibrated directly from compression tests (see the following section) and the value of $a_{1}$ is always larger than zero. The influence of this fitting parameter $\left(a_{1}\right)$ on the yield surface is shown in Fig. 1 in Zhou et al. [51]. Eq. (4) is certainly not the only possible choice for $\lambda\left(S_{\rho}\right)$, but it is perhaps one of the simplest expressions for a non-linear interpolation. In practical applications, if the compression index $\left(\lambda_{d}\right)$ is not available, it can be assumed, for fine-grained soil, to be equal to the elastic value $(\kappa)$ :

\section{$\lambda\left(S_{\rho}\right)=\lambda_{0}-\left(\lambda_{0}-\kappa\right)\left(1-S_{\rho}\right)^{a_{1}}$}

Such a simplification may lead to some overestimation of the shear strength. However, the experimental validations below will indicate that such a simplification is still acceptable. For coarse-grained soil, such as sand, $\lambda_{d}$ can be assumed, if no data is available, as about 0.5

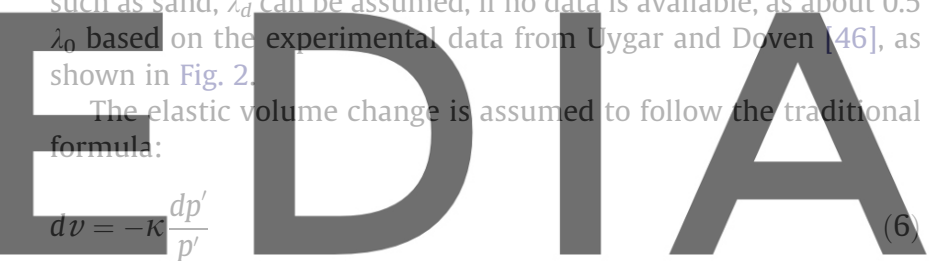

where $\kappa$ is the recompression index for the saturated soil and does

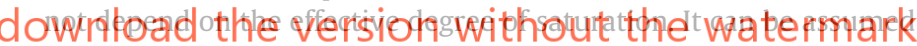
as a fraction (5-10\%) of $\lambda$ if $\kappa$ is not known. The parameter $\kappa$ usually does not affect the calibration and prediction significantly since it is very small compared to $\lambda$.

The volume change Eq. (3) can be rewritten in an incremental form as:

$-d v=\lambda\left(S_{e}\right) \frac{d p^{\prime}}{p^{\prime}}+\frac{\partial \lambda\left(S_{e}\right)}{\partial S_{e}} \ln p^{\prime} d S_{e}$

Eq. (7) indicates that the volume change can consist of two parts: the first part is due to the stress change and the second part is due to the change of the effective degree of saturation. If $S_{e}$ is fixed (such as loading under the saturated or the driest condition), the second term on the right hand side of above equation will degenerate to zero. In this case, Eq. (7) defines the normal compression lines without the bonding/debonding effect. It also indicates that the bonding effect due to drying can be weakened or eliminated by raising the effective degree of saturation. In other words, an unsaturated soil can be de-structured/debonded by soaking it in water, and a saturated soil can be structured/bonded by desaturation.

Eq. (7) can be understood by inspecting Fig. 6. In the loading process under a constant suction, the second term of Eq. (7), which describes the debonding effect, is always larger than zero since $\mathrm{d} S_{e}$ $\geqslant 0$. As shown in Fig. 6 , although $\lambda\left(S_{e}\right)$ is less than $\lambda_{0}$, the apparent slope of the compression curve for an initially unsaturated soil can still be larger than that for its saturated counterpart $\left(\lambda_{0}\right)$ because of the debonding effect.

A typical drying-loading process can be explained by Eq. (3) or Eq. (7), as shown in Fig. 7. For example, a reconstituted soil is consolidated from the slurry state (point $\mathrm{A}$ ) to a preconsolidation 


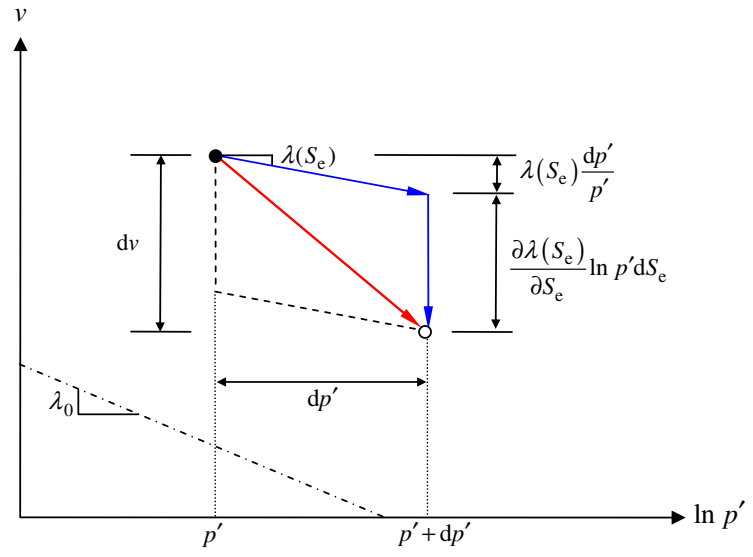

Fig. 6. Volume change of partially saturated soils with debonding.

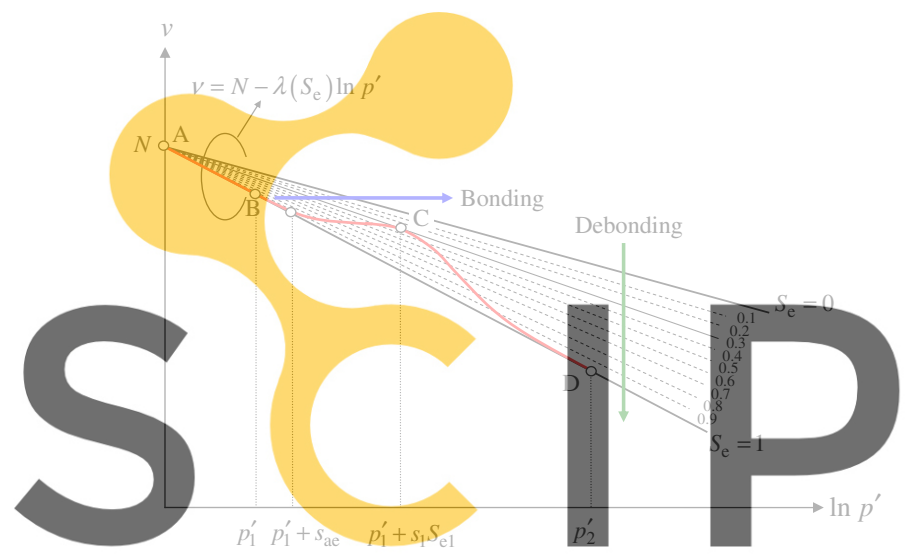

Fig. 7. Bonding and debonding effects during a typical drying-loading path and

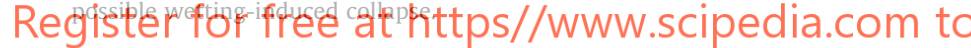

pressure $p_{1}^{\prime}$ (point B). The soil sample is then dried to the suction level $s_{1}$ (point $\mathrm{C}$, the corresponding effective degree of saturation is $\left.S_{e 1}\right)$, where the air entry value is assumed as $s_{a e}\left(<s_{1}\right)$. The specimen is finally compressed under a constant suction level to a higher pressure $\left(p_{2}^{\prime}\right)$ at point D. Fig. 7 shows that the bonding effect is reinforced via the decreasing value of $S_{e}$ during the drying process from B to C, but weakened via the increasing value of $S_{e}$ during the loading process from $C$ to $D$. When the soil becomes fully saturated, the bonding effect is completely removed and the soil recovers the normally consolidated saturated state. Hence the normal compression line with a constant suction level (such as $s_{1}$ ) will approach the NCL for the saturated state. This prediction is consistent with the test data of Jotisankasa [16] (see Fig. 5).

\subsection{Calibration for the new parameter}

The new parameter $\left(a_{1}\right)$ defines the influence of the effective degree of saturation on the compressibility of unsaturated soils. It can be calibrated by conventional isotropic compression tests (suction-controlled compression or undrained compression). In the following, the experimental results of a suction-controlled oedometer test from Honda [13] are used as an example to demonstrate the calibration process for $a_{1}$. For this series of data, the residual degree of saturation $\left(S_{r}^{\text {res }}\right)$ is unknown and assumed to be zero for simplicity. In this case, $S_{e}=S_{r}$. As shown in Fig. 8, the elastic compression index $(\kappa)$ can be determined by the data points on the elastic loading part and the data points on the elastoplastic

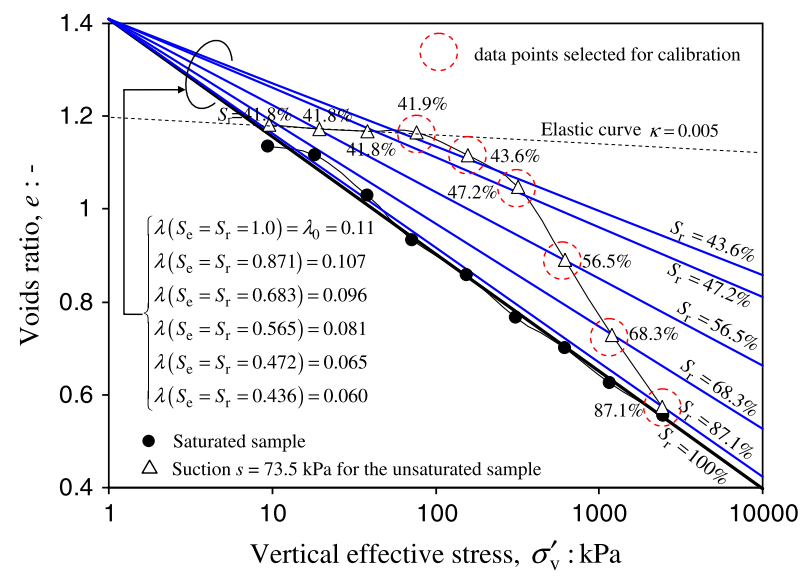

Fig. 8. Normal compression lines and experimental data (data after [13].

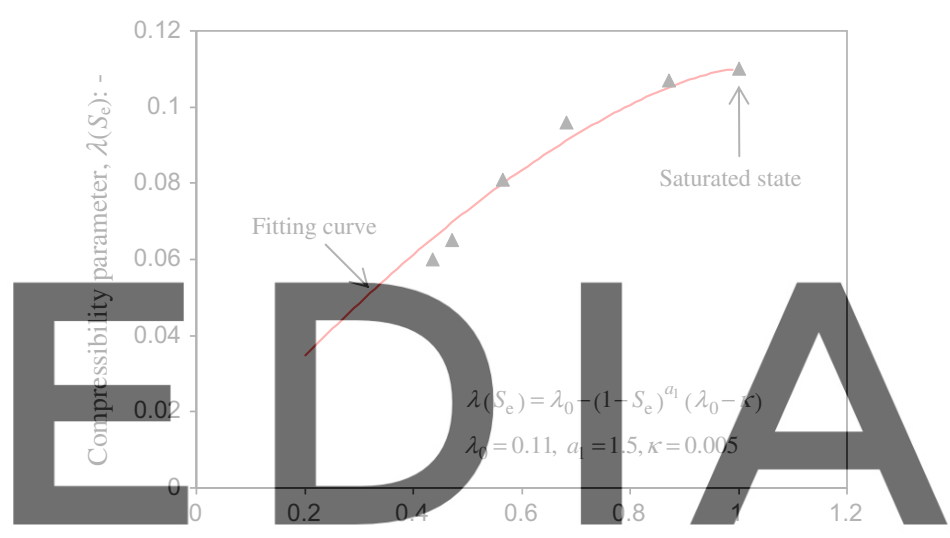

Effective degree of saturation, $S_{\mathrm{e}}: \%$

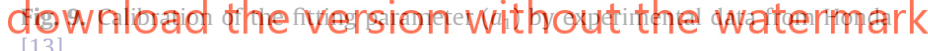

loading part are selected to calibrated this new parameter $\left(a_{1}\right)$. we can obtain the tangent compression indices for different effective degrees of saturation (i.e. selected data points in the elastoplastic loading part) from compression tests. The corresponding compression index, $\lambda\left(S_{e}\right)$, is replotted against the effective degree of saturation for each selected data point (see Fig. 9) to calibrate the parameter $\left(a_{1}\right)$ using Eq. (5).

\subsection{Validation of the volume change equation: drained and undrained tests}

The validation of the proposed volume change equation (i.e. Eq. (3)), is based on different sets of data from laboratory experiments. The first data set is from Sharma [30], where a series of isotropic compression tests were performed at different suctions $(100,200$ and $300 \mathrm{kPa}$, respectively). During these tests, both the mechanical response (change in the specific volume) and the hydraulic response (change in the degree of saturation) were measured. The normal compression line for the saturated specimen is characterised by an $N$ of 2.915 and a $\lambda_{0}$ of 0.173 (as for the data sets by Sharma [30] did not contain virgin loading tests on saturated samples, the values of $N$ and $\lambda$ were assumed within a reasonable range). Again, the residual degree of saturation $\left(S_{r}^{\text {res }}\right)$ is set to zero for simplicity. Fig. 10 shows the normal compression test results at constant suctions of 100,200 and $300 \mathrm{kPa}$, as well as the estimated normal compression line for the saturated soil in $v$ - In $\mathrm{p}^{\prime}$ space. 


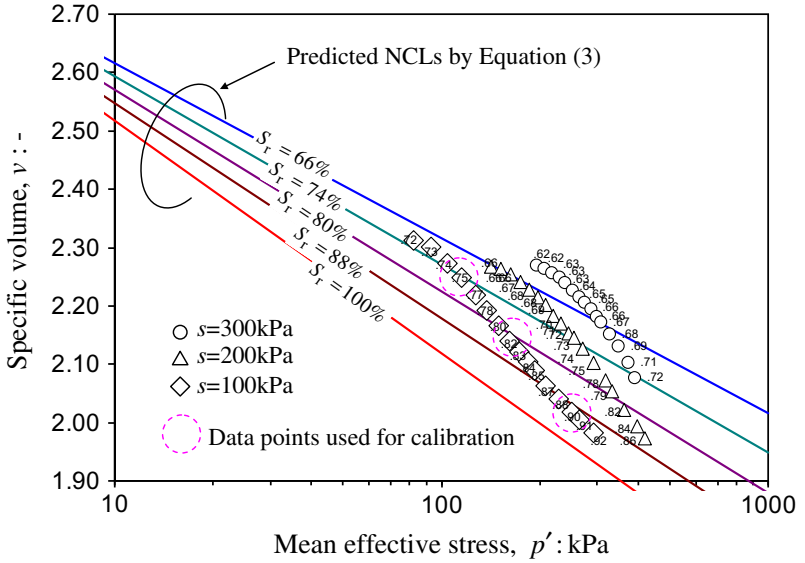

Fig. 10. Isotropic compression test data of silty clay under constant suctions (data after $[30]$ and predicted normal compression lines by Eq. (3).

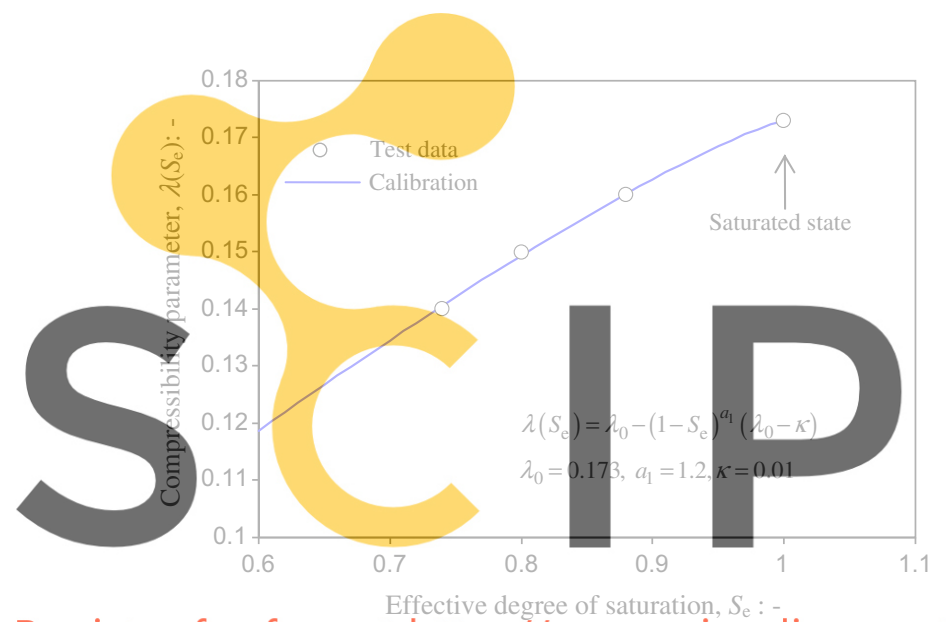

Register for free at https//WwW. Scipedia.com to (suction $=100 \mathrm{kPa}$ ) from $[30]$

The first test data for a suction of $100 \mathrm{kPa}$ are used to calibrate Eq. (3). As shown in Fig. 10, three arbitrary data points in this series are selected (the degrees of saturation of these points are $74 \%, 80 \%$, and $88 \%$, respectively.), and the compression indices for these three points are calibrated as $0.14,0.15$, and 0.16 , respectively. The calibration for the new parameter is illustrated in Fig. 11. According to the calibration, the coupling parameter $\left(a_{1}\right)$ is set to 1.2. After the calibration, the normal compression lines at constant degrees of saturation are plotted in Fig. 10. Eq. (3) is then used to predict the other two series of tests in Fig. 12. From the comparison, it can be seen that the calibration method is effective and the predictions from Eq. (3) agree with the measurements very well.

Suction-monitored undrained oedometer results from Jotisankasa [16] are now adopted to validate the proposed volume change equation above. Because the $K_{0}$ value is unknown, the isotropic compression index is assumed to be the same as the oedometer compression index i.e., $\lambda \approx C_{c}$. Series $7-10$-SL (saturated), $7-10-\mathrm{H}$ (initial gravitational water content $13.5 \%$ ) and $7-10-\mathrm{G}$ (initial gravitational water content $14.8 \%$ ) are replotted in the $v-\operatorname{In} \sigma_{v}^{\prime}$ plane as shown in Fig. 13. From the test data of series 7-10-SL (saturated), $N$ is set to 1.94 and $\lambda_{0}$ is set to 0.0725 . The residual degree of saturation $\left(S_{r}^{\text {res }}\right)$ is again set to zero for simplicity. Series $7-10-\mathrm{H}$ is used to calibrate Eq. (3). As shown in Fig. 13, four points (with degrees of saturation of $51 \%, 55 \%, 68 \%$, and $82 \%$ ) are selected and their respective compression indices are calibrated as $0.046,0.049,0.062$, and 0.068 . The

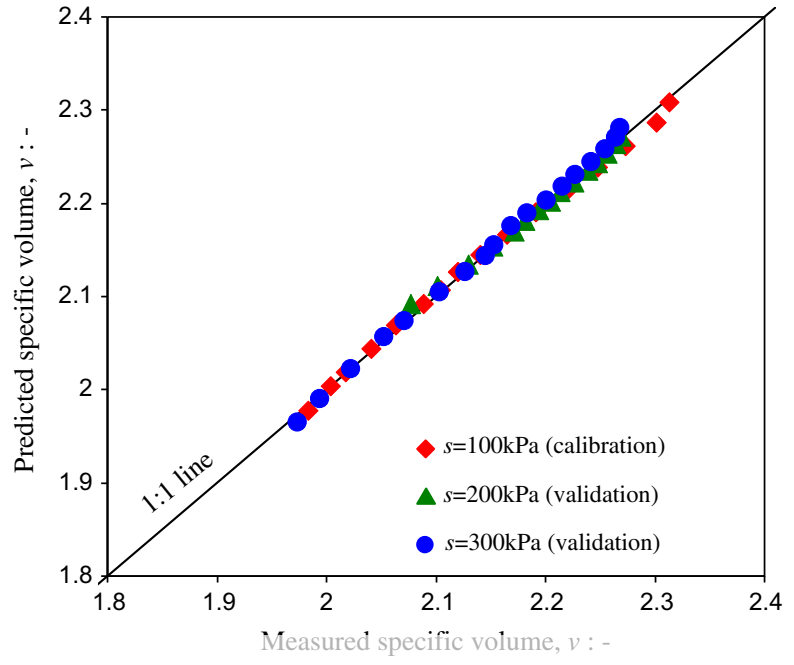

Fig. 12. Comparisons between the measured and predicted specific volume (data after [30].

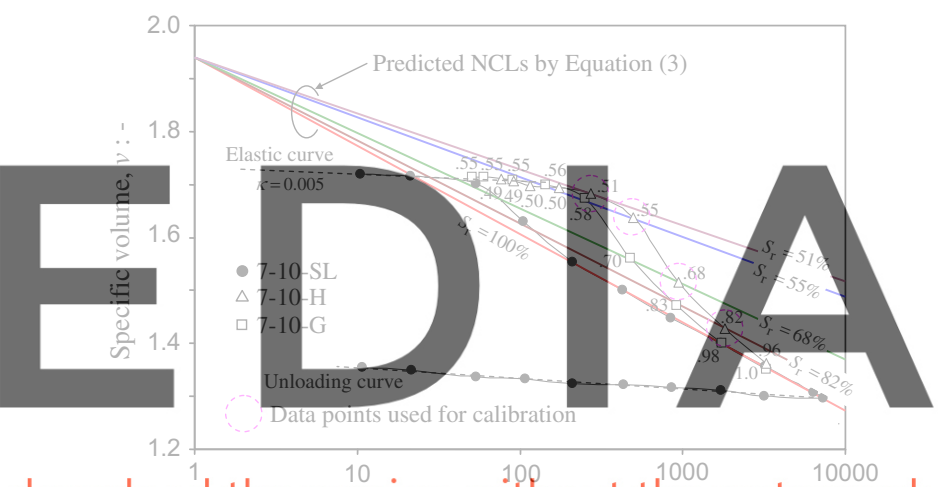

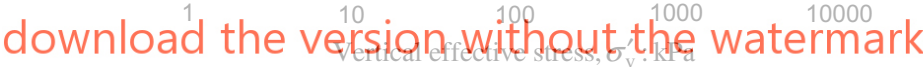

Fig. 13. Water content controlled oedometer test data (data after [16] and predicted normal compression lines by Eq. (3).

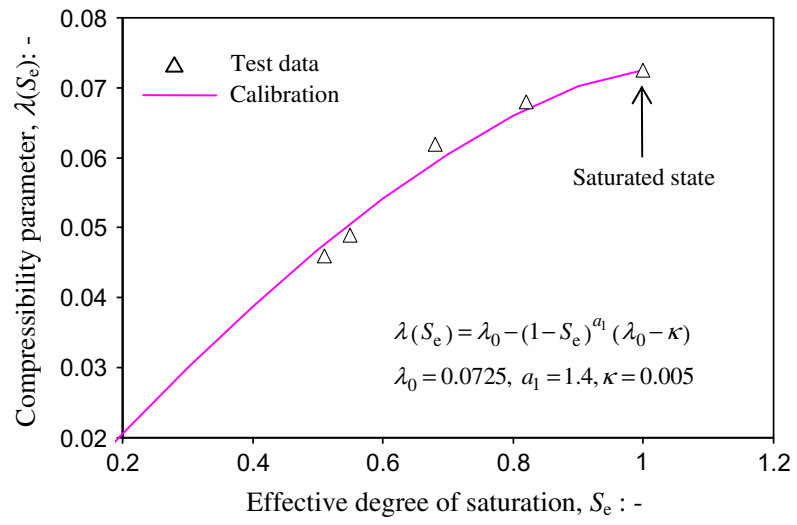

Fig. 14. Calibration of the fitting parameter $(A 1)$ in Eq. (3) by series $7-10-\mathrm{H}$ (data after [16].

calibration of the new parameter $\left(a_{1}\right)$ is illustrated in Fig. 14, leading to a value of 1.4. After the calibration, the normal compression lines for constant degrees of saturation are plotted in Fig. 13. The measured value of specific volume for each data point on the normal compression lines is compared with the predicted value in Fig. 15, 


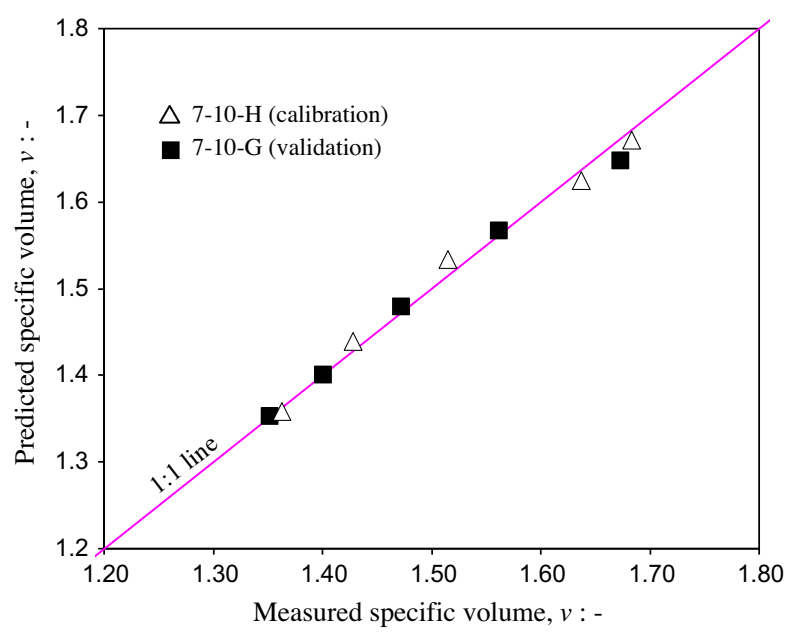

Fig. 15. Comparisons between the measured and predicted specific volume (data after [16].

which indicates the predictions of Eq. (3) match the measurements very well.

\section{Hydraulic behaviour}
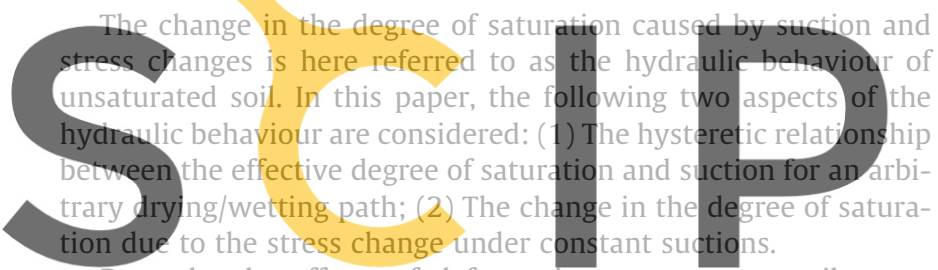

Recently, the effects of deformation or stress on soil-water characteristic curves (SWCCS) have been highlighted in coupled

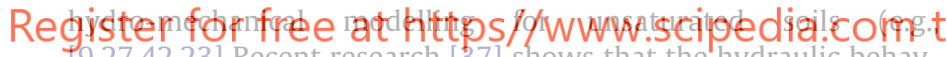
iour is governed by the suction as well as the volumetric strain due to net stresses $\left(\varepsilon_{v \sigma}\right)$. The change of the degree of saturation can be expressed conceptually as follows:

$d S_{r}=\frac{\partial S_{r}}{\partial s} d s+\frac{\partial S_{r}}{\partial \varepsilon_{v \bar{\sigma}}} d \varepsilon_{v \bar{\sigma}}=\frac{\partial S_{r}}{\partial s} d s+D d \varepsilon_{v \bar{\sigma}}$

where $D=\partial S_{\mathrm{r}} / \partial \varepsilon_{v \bar{\sigma}}$. $D$ is a general function that defines the influence of the volumetric strain due to the net stress change $\left(d \varepsilon_{v \bar{\sigma}}\right)$ on the degree of saturation. For triaxial stress states, the volumetric strain due to the net stress change $\left(d \varepsilon_{v \bar{\sigma}}\right)$ is caused by changes in both the mean net stress and the deviator stress. Sheng and Zhou [37] specified the general function $D$ based on some intrinsic constraints for a three-phase mixture and validated the resulting formula against experimental data. Replacing the degree of saturation $\left(S_{r}\right)$ by the effective one $\left(S_{e}\right)$ via equation, the above equation can be rewritten as

$d S_{e}=\frac{\partial S_{e}}{\partial s} d s+\frac{D}{1-S_{r}^{\text {res }}} d \varepsilon_{v \bar{\sigma}}=\frac{\partial S_{e}}{\partial s} d s+D_{e} d \varepsilon_{v \bar{\sigma}}$

where $D_{e}$ is a general function that defines the effect of volumetric strain on the effective degree of saturation that is caused by a net stress change $\left(d \varepsilon_{v \bar{\sigma}}\right)$. When $S_{\mathrm{r}}^{\text {res }}$ is equal to zero, $D_{e}$ is identical to $D$. The first term on the right-hand side of Eq. (9) accounts for the change of the effective degree of saturation under a constant net stress. The standard laboratory water retention test can be used to calibrate this term directly. The volumetric strain caused by a suction change under a constant net stress is already contained in this term. The second term on the right-hand side accounts for the change of the effective degree of saturation due to the net stress under a constant suction. A suction-controlled compression test can be used to determinate this term. The two terms on the right-hand side of Eq. (9) will be discussed separately below.

\subsection{Hydraulic hysteresis under constant stresses}

Extensive research has been done on soil-water characteristic curves under constant net stresses (i.e. the first term on the right-hand side of Eq. (9)), both in the fields of soil physics and geotechnical engineering. Numerous empirical equations have been proposed in the literature (e.g. [10,4,26,47,7]. van Genuchten's equation is adopted in this paper as an example of a soil-water characteristic curve (for both the main drying curve and the main wetting curve) under constant net stresses. The relevant equations for the main drying branch $\left(S_{e d}\right)$ and the main wetting branch $\left(S_{e w}\right)$ are
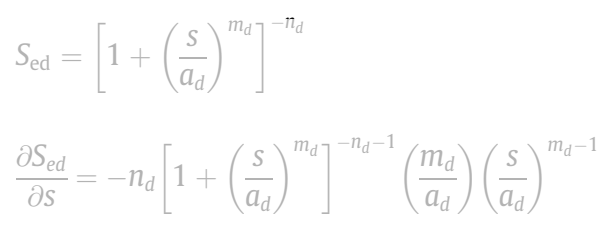

and

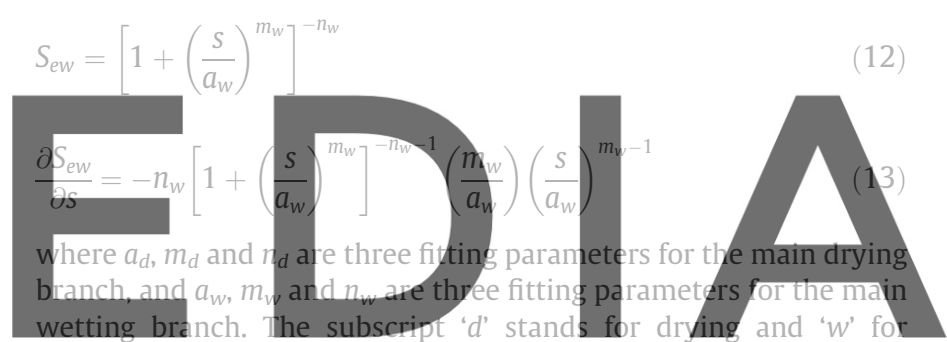

wetting.

A simple boundary scanning rule is adopted here to describe the

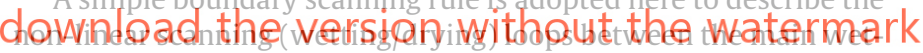
ting and drying branches. Similar approaches can be found in Li [21] and Pedroso et al. [28]. A projection centre is needed to define the mapping rule for the scanning curve in Li [21]. Our method does not involve this 'projection centre'.

The main drying curve and the main wetting curve are selected as the drying and wetting boundaries. As shown in Fig. 16, wetting from the current point $\left(s, S_{e}\right)$, the scanning gradient is defined by the following equation:

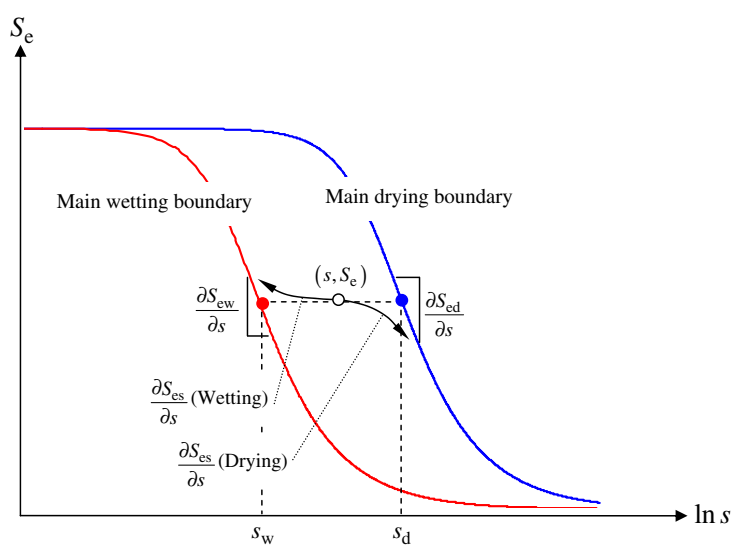

Fig. 16. Main drying/wetting boundaries and scanning law. 

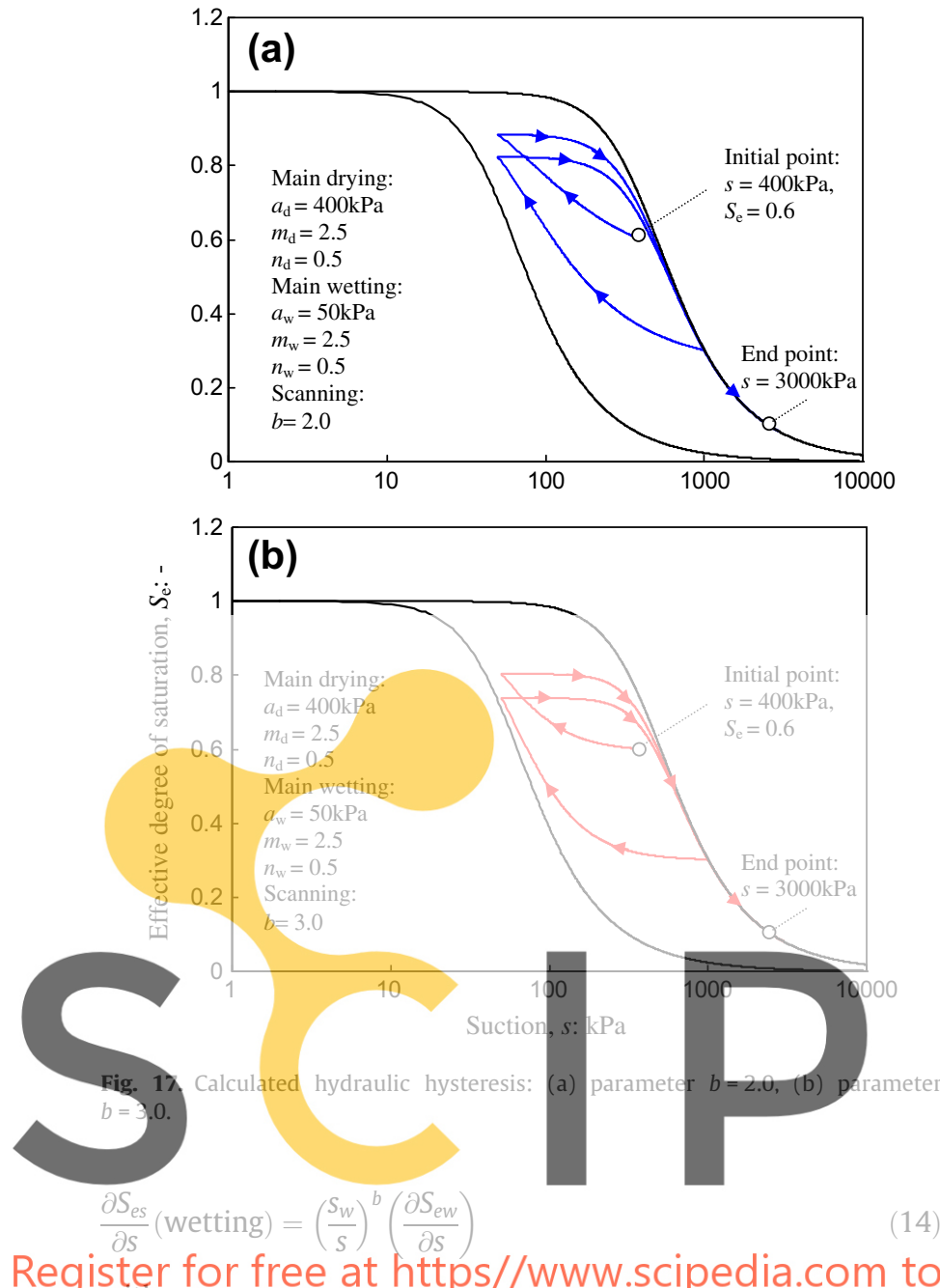

Register for free at https//www.scipedia.com to d

$S_{w}=a_{w}\left(S_{\rho}^{-1 / n_{w}}-1\right)^{1 / m_{W}}$

where $s_{w}$ is the suction corresponding to the wetting boundary at the same effective degree of saturation as the current point and the subscript 's' stands for scanning. Drying from the current point $\left(s, S_{e}\right)$, the scanning gradient is defined similarly as

$\frac{\partial S_{e s}}{\partial s}($ drying $)=\left(\frac{s_{d}}{s}\right)^{-b}\left(\frac{\partial S_{e d}}{\partial s}\right)$

with

$s_{d}=a_{d}\left(S_{e}^{-1 / n_{d}}-1\right)^{1 / m_{d}}$

where $s_{d}$ is the suction corresponding to the drying boundary at the same effective degree of saturation as the current point. Here, $b$ is a fitting parameter (always positive) which adjusts the gradient of the scanning curve. The predicted scanning curve is the same as the primary branch when $b=0$. When it approaches infinite $(b=+\infty)$, the predicted scanning curve is a straight line horizontal to the suction axis. For simplicity, we assume here that this fitting parameter is the same for both drying and wetting. When the current point moves towards the wetting/drying boundaries, the gradient of the scanning curve approaches that of the main wetting/ drying curves. In the proposed hysteretic model, there are seven parameters in total: 3 for the main drying branch $\left(a_{d}, m_{d}\right.$ and $\left.n_{d}\right)$, 3 for the main wetting branch $\left(a_{w}, m_{w}\right.$ and $\left.n_{w}\right)$, and one for the scanning $(b)$. Fig. 17 shows simulated wetting/drying loops for the proposed scanning law. The initial suction and initial degree of saturation are assumed to be $400 \mathrm{kPa}$ and $60 \%$, respectively. Firstly,

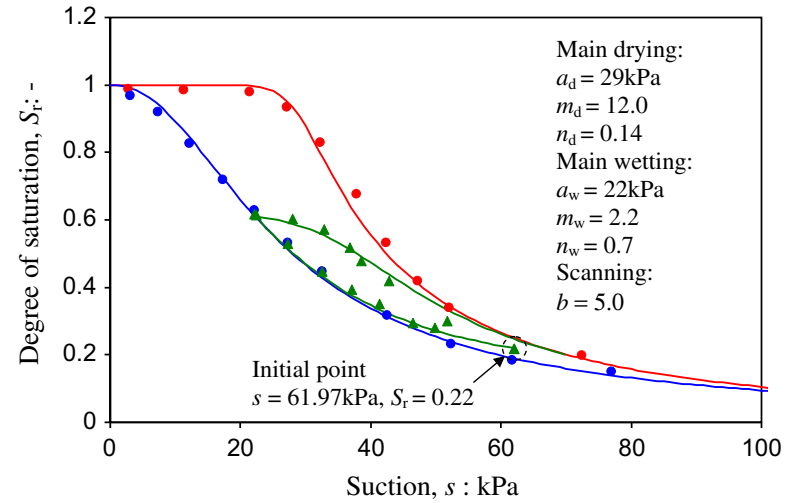

Fig. 18. Measured hydraulic hysteresis of a sand sample (data after [48] and predictions by Eqs. (14) and (16).

the soil is wetted to $50 \mathrm{kPa}$ from the initial state, and then dried to a suction of $1000 \mathrm{kPa}$. After that, the soil is wetted again from a suction of $1000 \mathrm{kPa}$ down to $50 \mathrm{kPa}$, and then dried to $3000 \mathrm{kPa}$. The hysteretic behaviour calculated by Eqs. (14) and (16) with different values of parameter $b$ is illustrated in Fig. 17. From Fig. 17, we can find that the value of parameter $b$ controls the tangent slope of scanning curve. The smaller value of parameter $b$ will generate 'softer' scanning curve.

Viaene et al. [48] presented a wetting-drying test on a sand

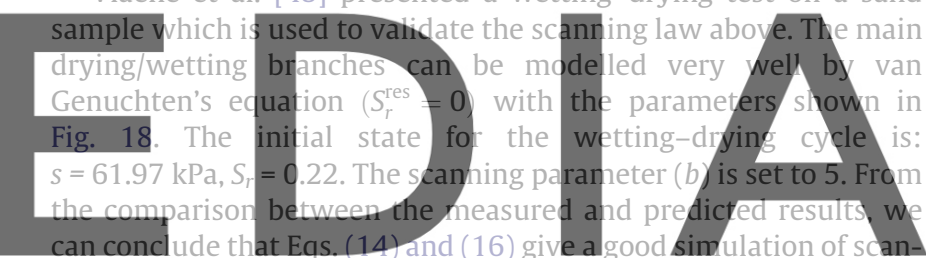

ning (wetting/drying) loops.

\section{download the version without the watermark 3.2. Hydro-mechanical interaction under constant suctions}

The second term on the right-hand side of Eq. (9) reflects the effect of the mechanical properties on the hydraulic response (i.e. the hydro-mechanical interaction). Experimental results show that mechanical loading under a constant suction leads to an increase in the degree of saturation (see Fig. 8). The general function $\left(D_{e}\right)$ in Eq. (9) defines the relationship between the effective degree of saturation and the volumetric strain due to net stress changes. Analogous to the general function $D$ in Eq. (8), $D_{e}$ can also be

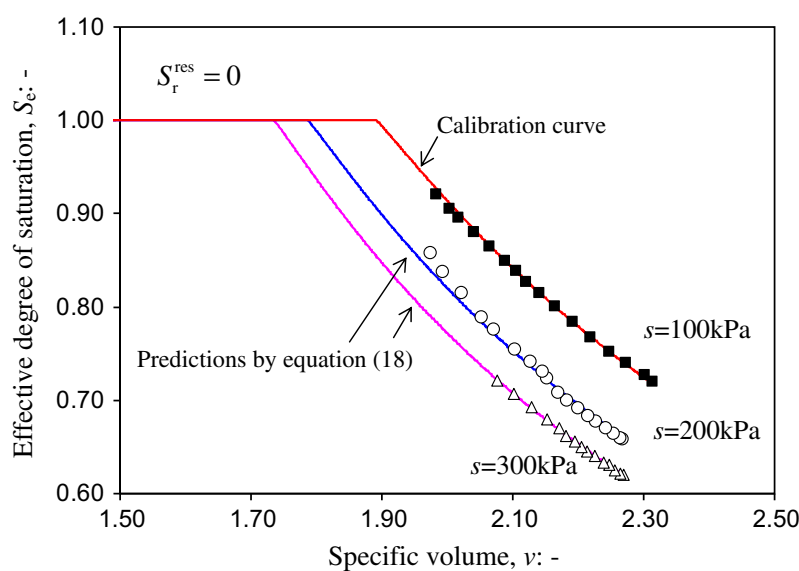

Fig. 19. Calibration and validations of Eq. (18) using Sharma's data [30]. 
investigated by suction-controlled compression tests and takes the similar form:

$D_{e}=\frac{S_{e}(1+e)}{e}\left(1-S_{e}\right)^{a_{2}}$

where $a_{2}$ is a fitting parameter that defines the variation of $S_{e}$ under constant suctions. When $S_{r}^{\text {res }}=0$, we have $S_{r}=S_{e}$ and $D=D_{e}$.

Fig. 19 gives an example to demonstrate the determination of the fitting parameter $\left(a_{2}\right)$ in Eq. (18). This Figure shows the experimental results from suction-controlled isotropic compression tests performed by Sharma [30], which are replotted in the plane of $S_{e}-v$. The $100 \mathrm{kPa}$ suction data set (black square points) is used to calibrate the fitting parameter $\left(a_{2}\right)$ in Eq. (18). As shown in Fig. 19, this gives an $a_{2}$ value of 0.07 . The remaining two data sets (at suctions of $200 \mathrm{kPa}$ and $300 \mathrm{kPa}$ ) are used to validate Eq. (18). Both the calibration and validation curves are shown in Fig. 19. The good predictions confirm the validity of Eq. (18). The detailed analysis and validation of the general function $(D)$ can be found in Sheng and Zhou [37].

\section{Concluding remarks}

This paper presents a new approach to model the volume change and water retention behaviour of unsaturated soils. The proposed approach is characterised by the following properties:

(1) A new volume change equation is proposed in the plane of

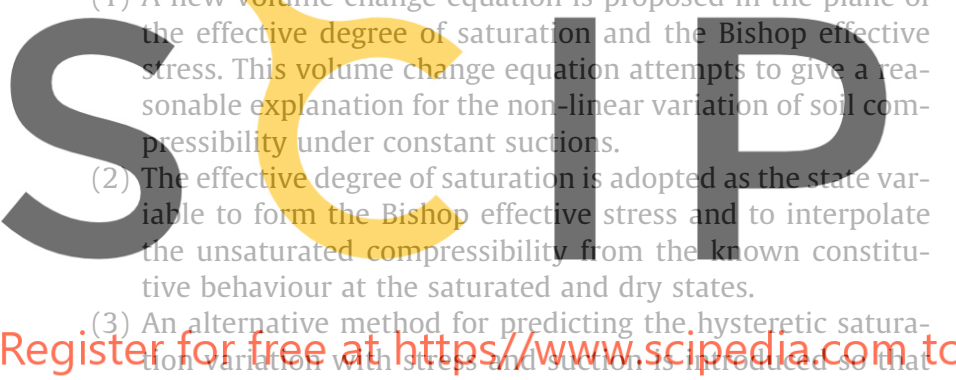
the effective degree of saturation under complex stress-suction paths can be calculated. This method together with the volume change equation constitutes the bases of a complete constitutive model for coupled hydro-mechanical behaviour of unsaturated soils (see [51]).

(4) Both the volume change and water retention equations are compared against a wide variety of experimental data in the literature. The comparison shows that the proposed equations give reasonable predictions of volume and saturation changes caused by stress and suction changes.

\section{References}

[1] Alonso EE, Gens A, Josa A. A constitutive model for partially saturated soils. Geotechnique 1990;40(3):405-30.

[2] Bishop AW. The principle of effective stress. Teknisk Ukeblad 1959;106(39):859-63.

[3] Bolzon G, Schrefler BA, Zienkiewicz OC. Elastoplastic soil constitutive laws generalised to partially saturated states. Geotechnique 1996;46(2):279-89.

[4] Brooks R, Corey A. Hydraulic properties of porous media. Hydrology paper, no. 3. Fort Collins, Colorado: Colorado State University; 1964

[5] Chiu CF, Ng CWW. A state-dependent elasto-plastic model for saturated and unsaturated soils. Geotechnique 2003;53(9):809-29.

[6] Cui YJ, Delage P. Yielding and plastic behaviour of an unsaturated compacted silt. Geotechnique 1996;46(2):291-311.

[7] Fredlund DG, Xing A. Equations for the soil-water characteristic curve. Can Geotech J 1994;31(3):521-32.

[8] Gallipoli D, Gens A, Sharma R, Vaunat J. An elastoplastic model for unsaturated soil incorporating the effects of suction and degree of saturation on mechanical behaviour. Geotechnique 2003;53(1):123-35.

[9] Gallipoli D, Wheeler SJ, Karstunen M. Modelling of variation of degree of saturation in a deformable unsaturated soil. Geotechnique 2003;53(1):105-12.
[10] Gardner W. Mathematics of isothermal water conduction in unsaturated soils Highway research board special report 40. In: International symposium on physico-chemical phenomenon in soils, Washington, DC; 1956. p. 78-87.

[11] Gens A. Soil-environment interactions in geotechnical engineering. Geotechnique 2010;60(1):3-74.

[12] Georgiadis K, Potts DM, Zdravkovic L. Three-dimensional constitutive model for partially and fully saturated soils. Int J Geomech 2005;5(3):244-55.

[13] Honda M. Research on the prediction methods for the mechanical behaviors of unsaturated soils. PhD thesis, Kobe University, Kobe, Japan; 2000.

[14] Josa A, Alonso EE, Lloret A, Gens A. Stress-strain behaviour of partially saturated soils. In: Proceedings of 9th European conference on soil mechanics and foundation engineering, Dublin, vol. 2; 1987. p. 561-4.

[15] Josa A, Balmaceda A, Gens A, Alonso EE. An elastoplastic model for partially saturated soils exhibiting a maximum of collapse. In: Owen DRJ, Onate E Hinton E, editors. Computational plasiticity III, vol. 1. Swansea: Pineridge Press; 1992 . p. $815-26$.

[16] Jotisankasa A. Collapse behaviour of a compacted silty clay. PhD thesis London: Imperial College London; 2005.

[17] Kikumoto M, Kyokawa H, Nakai T, Shahin HM. A simple elasto-plastic mode for unsaturated soils and interpretations of collapse and compaction behaviors. In: Alonso EE, Gens A, editors. Unsaturated soils, vol. 2. Barcelona Spain: CRC Press; 2011. p. 849-55.

[18] Kohgo Y, Nakano M, Miyazaki T. Theoretical aspects of constitutive modelling for unsaturated soils. Soils Found 1993;33(4):49-63

[19] Li JZ, Peng FL, Xu LS. One-dimensional viscous behavior of clay and its constitutive modeling. Int J Geomech 2009;9(2):43-51.

[20] Li JZ, Peng FL, Xu LS, Tatsuoka F. Viscous properties of clay with different wate content. Soil and rock behavior and modeling (GSP 150), vol. 194. Shanghai, China: ASCE; 2006. p. 55-61

21] Li XS. Modelling of hysteresis response for arbitrary wetting/drying paths. Comput Geotech 2005;32(2):133-7

[22] Loret B, Khalili N. An effective stress elastic-plastic model for unsaturated porous media. Mech Mater 2002;34(2):97-116.

[23] Masin D. Predicting the dependency of a degree of saturation on void ratio and suction using effective stress principle for unsaturated soils. Int J Numer Anal
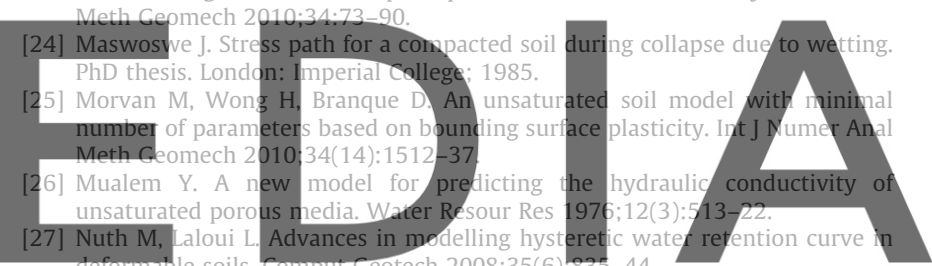

28] Pedroso DM, Sheng D, Zhao J. The concept of reference curves for constitutive modelling in soil mechanics. Comput Geotech 2008:36(1):149-65.

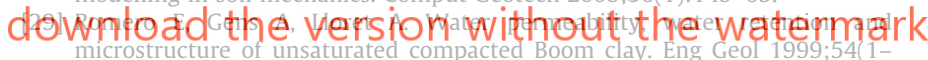
2):117-27

301 Sharma R. Mechanical behaviour of unsaturated highly expansive soil. PhD thesis. UK: University of Oxford; 1998.

[31] Sheng D. Review of fundamental principles in modelling unsaturated soil behaviour. Comput Geotech 2011;38:757-76.

[32] Sheng D, Fredlund DG, Gens A. A new modelling approach for unsaturated soils using independent stress variables. Can Geotech J 2008;45(4):511-34.

[33] Sheng D, Gens A, Fredlund DG, Sloan SW. Unsaturated soils: from constitutive modelling to numerical algorithms. Comput Geotech 2008;35(6):810-24.

[34] Sheng D, Sloan SW, Gens A. A constitutive model for unsaturated soils: thermomechanical and computational aspects. Comput Mech 2004;33(6):453-65.

[35] Sheng D, Sloan SW, Gens A, Smith DW. Finite element formulation and algorithms for unsaturated soils. Part I: theory. Int J Numer Anal Meth Geomech 2003;27(9):745-65.

[36] Sheng D, Smith DW, Sloan SW, Gens A. Finite element formulation and algorithms for unsaturated soils. Part II: verification and application. Int J Numer Anal Meth Geomech 2003;27(9):767-90.

[37] Sheng D, Zhou AN. Coupling hydraulic with mechanical models for unsaturated soils. Can Geotech J 2011;48(5):826-40

[38] Sivakumar V. A critical state framework for unsaturated soils. PhD thesis Sheffield: University of Sheffield; 1993.

[39] Sivakumar V, Wheeler SJ. Influence of compaction procedure on the mechanical behaviour of an unsaturated compacted clay. Part 1: wetting and isotropic compression. Geotechnique 2000;50(4):359-68.

[40] Sun DA, Sheng D, Sloan SW. Elastoplastic modelling of hydraulic and stressstrain behaviour of unsaturated soils. Mech Mater 2007;39(3):212-21.

[41] Sun DA, Sheng D, Xu XF. Collapse behaviour of unsaturated compacted soil. Can Geotech J 2007;44:673-86.

[42] Tarantino A. A water retention model for deformable soils. Geotechnique 2009;59(9):751-62.

[43] Thu TM, Rahardjo H, Leong EC. Critical state behavior of a compacted silt specimen. Soils Found 2007;47(4):749-55.

[44] Toll DG. A framework for unsaturated soil behaviour. Geotechnique 1990;40(1):31-44

[45] Toll DG, Ong BH. Critical state parameters for an unsaturated residual sandy clay. Geotechnique 2003;53(1):93-103. 
[46] Uygar E, Doven AG. Monotonic and cyclic oedometer tests on sand at high stress levels. Granular Matter 2006;8(1):19-26.

[47] van Genuchten MT. A closed-form equation for predicting the hydraulic conductivity of unsaturated soils. Soil Sci Soc Am J 1980;44:892-8.

[48] Viaene P, Vereecken H, Diels J, Feyen J. A statistical analysis of six hysteresis models for the moisture retention characteristic. Soil Sci 1994;157(6): 345-55.
[49] Wheeler SJ. Inclusion of specific water volume within an elsto-plastic model for unsaturated soil. Can Geotech J 1996;33(1):42-57.

[50] Wheeler SJ, Sharma RS, Buisson MSR. Coupling of hydraulic hysteresis and stress-strain behaviour in unsaturated soils. Geotechnique 2003;53(1):41-54.

[51] Zhou AN, Sheng D, Scott SW, Gens A. Interpretation of unsaturated soil behaviour in the stress-saturation space. II: Constitutive relationships and validations. Comput Geotech 2012;43:111-23.
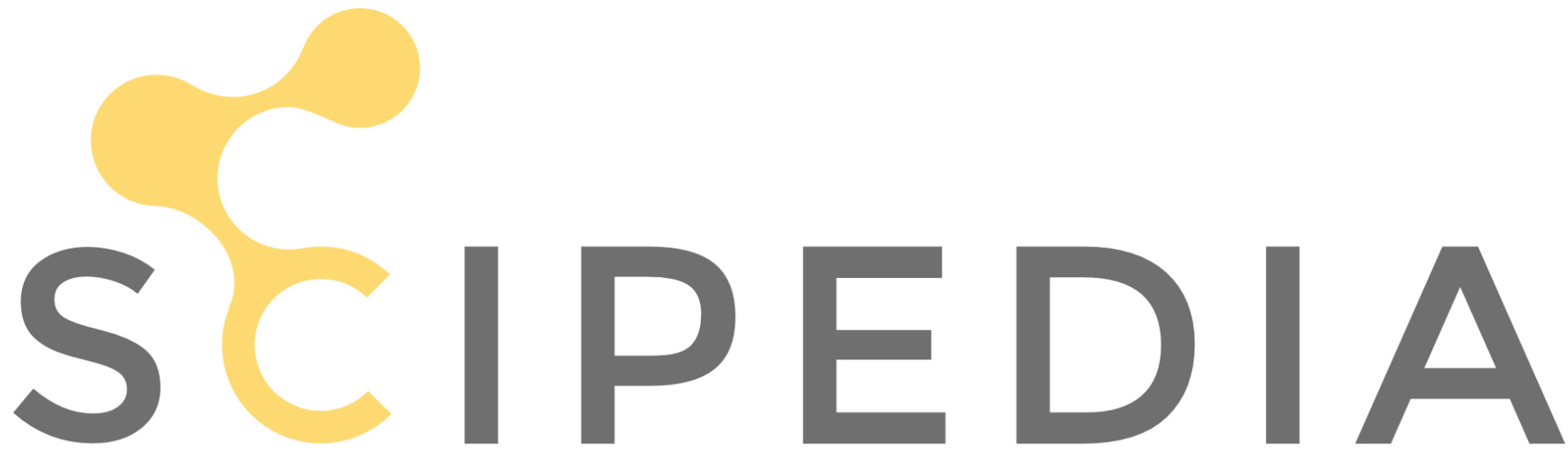

Register for free at https//www.scipedia.com to download the version without the watermark 